\title{
The Swiss cohort of elderly patients with venous thromboembolism (SWITCO65+): rationale and methodology
}

\author{
Marie Méan • Marc Righini · Kurt Jaeger · Hans-Jürg Beer • Beat Frauchiger • \\ Joseph Osterwalder $\cdot$ Nils Kucher • Bernhard Lämmle $\cdot$ Jacques Cornuz • \\ Anne Angelillo-Scherrer • Nicolas Rodondi • Andreas Limacher • \\ Sven Trelle - Christian M. Matter - Marc Husmann - Martin Banyai • \\ Markus Aschwanden • Michael Egloff • Lucia Mazzolai - Olivier Hugli • \\ Henri Bounameaux $\cdot$ Drahomir Aujesky
}

Published online: 29 January 2013

(C) Springer Science+Business Media New York 2013

\begin{abstract}
Venous thromboembolism (VTE) is common and has a high impact on morbidity, mortality, and costs of care. Although most of the patients with VTE are aged $\geq 65$ years, there is little data about the medical outcomes in the elderly with VTE. The Swiss Cohort of Elderly Patients with VTE (SWITCO65+) is a prospective multicenter cohort study of in- and outpatients aged $\geq 65$ years with acute VTE from all five Swiss university and four high-volume non-university hospitals. The goal is to examine which clinical and biological factors and processes of care drive short- and long-term medical outcomes, health-related quality of life, and medical resource utilization in elderly patients with acute VTE. The cohort also includes a large biobank with biological material from each participant. From September 2009 to March 2012,
\end{abstract}

M. Méan $(\bowtie) \cdot$ N. Rodondi · D. Aujesky

Division of General Internal Medicine, Bern University Hospital, Inselspital, 3010 Bern, Switzerland

e-mail: marie.mean@insel.ch

M. Righini · H. Bounameaux

Division of Angiology and Hemostasis, Geneva University

Hospital, Geneva, Switzerland

K. Jaeger · M. Aschwanden

Department of Angiology, Basel University Hospital, Basel,

Switzerland

H.-J. Beer · M. Egloff

Department of Internal Medicine, Cantonal Hospital of Baden,

Baden, Switzerland

B. Frauchiger

Department of Internal Medicine, Cantonal Hospital

of Frauenfeld, Frauenfeld, Switzerland
1,863 elderly patients with VTE were screened and 1003 $(53.8 \%)$ were enrolled in the cohort. Overall, $51.7 \%$ of patients were aged $\geq 75$ years and $52.7 \%$ were men. By October 16, 2012, after an average follow-up time of 512 days, $799(79.7 \%)$ patients were still actively participating. SWITCO65+ is a unique opportunity to study short- and long-term outcomes in elderly patients with VTE. The Steering Committee encourages national and international collaborative research projects related to SWITCO65+, including sharing anonymized data and biological samples.

Keywords Cohort study - Venous thromboembolism . Elderly patients · Biobank

\author{
J. Osterwalder \\ Emergency Department, Cantonal Hospital of St. Gallen, St. \\ Gallen, Switzerland \\ N. Kucher \\ Division of Angiology, Bern University Hospital, Bern, \\ Switzerland \\ B. Lämmle \\ Division of Hematology and Central Hematology Laboratory, \\ Bern University Hospital, Bern, Switzerland \\ J. Cornuz \\ Department of Ambulatory Care and Community Medicine, \\ Policlinique Médicale Universitaire, Lausanne, Switzerland
}

A. Angelillo-Scherrer

Service and Central Laboratory of Hematology,

Lausanne University Hospital, Lausanne, Switzerland 


\section{Introduction}

Acute venous thromboembolism (VTE), defined as deep vein thrombosis (DVT) and/or pulmonary embolism (PE), is a common disease and has a high impact on morbidity, mortality, and costs of care [1]. The annual incidence of VTE rises exponentially with age, from $<1$ case per 1,000 person-years in persons aged below 50 years to more than 6 cases per 1,000 person-years in persons aged above 80 years [2-5]. Overall, $60 \%$ of VTE cases occur in individuals aged $\geq 65$ years $[1,6]$.

Switzerland and other Western countries are facing a rapidly aging population [7]. Extrapolations from the Swiss Federal Statistical Office indicate that the proportion of persons aged over 65 years will increase from $17 \%$ in 2008 to $28 \%$ in 2060 [8]. The incidence and health burden of VTE is likely to increase with the expected growth of the elderly population [9].

Despite the significant public health impact of VTE in the elderly and growing evidence that VTE may have a less favourable course in elderly patients (e.g., higher recurrence, bleeding, and mortality rates) [6], older patients are underrepresented in randomized and nonrandomized prospective studies of VTE $[10,11]$. To date, little is known about the factors that determine medical outcomes, quality of life, and costs of care in the elderly with VTE. To fill this gap of knowledge, the National Institute of Health and international experts in the field called for VTE-related research in elderly patients [1, 12-14]. A prospective cohort study with long-term follow-up is the best methodological approach to examine the impact of risk factors and processes of care on patient outcomes because random assignment of risk factors is neither feasible nor ethical.

\section{A. Limacher $\cdot$ S. Trelle \\ Clinical Trials Unit, University of Bern, Bern, Switzerland}

C. M. Matter

Cardiovascular Research, Institute of Physiology, Zurich Center for Integrative Human Physiology, University of Zurich, Zurich, Switzerland

M. Husmann

Division of Angiology, Zurich University Hospital, Zurich, Switzerland

M. Banyai

Division of Angiology, Cantonal Hospital of Lucerne, Lucerne, Switzerland

\section{Mazzolai}

Service of Angiology, Lausanne University Hospital, Lausanne, Switzerland

O. Hugli

Emergency Department, Lausanne University Hospital,

Lausanne, Switzerland
Therefore, a group of academic investigators set up the Swiss Cohort of Elderly Patients with VTE (SWIT$\mathrm{CO65+)}$, a prospective multicenter cohort study of in- and outpatients aged 65 years or older with acute VTE from university and non-university hospitals in Switzerland. The goal of SWITCO65+ is to examine which clinical and biological factors and processes of care drive short- and long-term medical outcomes, health-related quality of life, and medical resource utilization in elderly patients with acute VTE. In this paper, we describe the study rationale, methods, and the patient population of SWITCO65+.

\section{Methods}

Study design

SWITCO65+ is a prospective multicenter cohort study of in- and outpatients aged 65 years or older with acute VTE from all five university (Basel, Bern, Geneva, Lausanne, and Zurich) and four high-volume non-university hospitals (cantonal hospitals of Baden, Frauenfeld, Luzern, and St. Gallen) in Switzerland. Only hospitals with $>250$ beds were considered to optimize enrollment of patients with VTE within sites and minimize the total number of hospitals required. The Ethics Committee at each participating center approved the study. SWITCO65+ is entirely funded by grants from the Swiss National Science Foundation (grant no. 33CSCO-122659/139470).

\section{Patients sample}

Patients were recruited from September 2009 to March 2012. Study nurses identified potential study subjects with VTE in the in- and outpatient services of all participating study sites. Consecutive patients aged 65 years or older with objectively diagnosed, symptomatic DVT or PE were eligible. Symptomatic DVT was defined as an acute onset of leg pain or swelling plus incomplete compressibility of a venous segment on ultrasonography or an intraluminal filling defect on contrast venography [15]. Because iliac veins and the inferior vena cava may be technically difficult to compress, additional diagnostic criteria for iliac and caval DVT also included abnormal duplex flow patterns compatible with thrombosis or an intraluminal filling defect on spiral computed tomography or magnetic resonance imaging venography [16-18]. Given that compression ultrasonography has a lower sensitivity and specificity for distal DVT [19], patients with isolated distal DVT were eligible only if the incompressible distal vein transverse diameter was at least $5 \mathrm{~mm} \mathrm{[20].}$

Symptomatic PE was defined as a positive spiral computed tomography or pulmonary angiography, a highprobability ventilation-perfusion scan, or proximal DVT 
documented by compression ultrasonography or contrast venography in patients with acute chest pain, new or worsening dyspnea, hemoptysis, or syncope [21, 22].

Exclusion criteria were inability to provide informed consent (i.e., severe dementia), conditions incompatible with follow-up (i.e., terminal illness or place of living too far away from the study center), insufficient German or French-speaking ability, thrombosis at a different site than lower limb, catheter-related thrombosis, or previous enrollment in the cohort.

Eligible patients who had no exclusion criteria were approached for informed consent to participate in the study. Because of collection and storage of biologic samples (including genetic material), patients were separately asked permission for future uses of these samples for genetic analyses related to VTE, with the specification that the investigators must obtain specific consent for any future use that is unrelated to VTE (tiered consent) [23]. Patients who initially refused participation because they were unwilling to come regularly back to the hospital for followup visits were offered home visits.

\section{Follow-up visits}

Follow-up includes one telephone interview and two surveillance face-to-face evaluations during the first year of study participation and then semi-annual contacts, alternating between face-to-face evaluations (clinic visits or home visits in house-bound patients) and telephone calls as well as periodic reviews of the patient's hospital chart (Table 1). During each visit/contact, study nurses interview patients to obtain information about the date and type of clinical events (recurrent VTE, bleeding, and death). If a clinical event has occurred, this information is complemented by reviewing medical charts and interviewing patients' primary care physicians and family members. During the baseline assessment and surveillance clinic visits, participants also undergo a brief clinical examination and generic and disease-specific quality of life assessments.

Study nurses at each study site prospectively collect clinical data, diagnostic and therapeutic processes of care, laboratory parameters, and information about health-related quality of life for all enrolled patients using standardized data collection forms (Table 2). In non-enrolled patients, anonymized demographic data were collected to assess the risk of a potential patient selection bias. The follow-up period will continue until December 2013.

\section{Outcomes}

The primary medical outcome is the recurrence of symptomatic, objectively confirmed VTE during the follow-up period, defined as new or recurrent PE or DVT (proximal and/or distal) based on previously published criteria $[22,24]$.

Secondary medical outcomes are the occurrence of major bleeding, all-cause mortality, and the postthrombotic syndrome (PTS) during the follow-up period [25-27]. We defined major bleeding as a fatal bleeding, a symptomatic bleeding in a critical organ (intracranial, intraspinal, intraocular, retroperitoneal, intraarticular, pericardial, or

Table 1 Data collection and follow-up schedule

\begin{tabular}{|c|c|c|c|c|c|c|c|c|c|c|}
\hline \multirow[t]{2}{*}{ Data Collection } & \multicolumn{10}{|c|}{ Study month } \\
\hline & Baseline & 3 & 6 & 12 & 18 & 24 & 30 & 36 & 42 & 48 \\
\hline \multicolumn{11}{|l|}{ Type of assessment } \\
\hline Face-to-face evaluation (at the hospital or during a home visit) & $\mathrm{X}$ & $\mathrm{X}$ & & $\mathrm{X}$ & & $\mathrm{X}$ & & $\mathrm{X}$ & & $\mathrm{X}$ \\
\hline Telephone interview & & & $X$ & & $\mathrm{X}$ & & $\mathrm{X}$ & & $\mathrm{X}$ & \\
\hline Review of the patient's hospital chart & $\mathrm{X}$ & $\mathrm{X}$ & $\mathrm{X}$ & $\mathrm{X}$ & $\mathrm{X}$ & $\mathrm{X}$ & $\mathrm{X}$ & $\mathrm{X}$ & $\mathrm{X}$ & $\mathrm{X}$ \\
\hline \multicolumn{11}{|l|}{ Parameter } \\
\hline Patient baseline characteristics & $\mathrm{X}$ & & & & & & & & & \\
\hline Initial VTE-related processes of care & $\mathrm{X}$ & $\mathrm{X}$ & & & & & & & & \\
\hline Assessment of VTE recurrence, bleeding, and death & & $\mathrm{X}$ & $\mathrm{X}$ & $\mathrm{X}$ & $\mathrm{X}$ & $\mathrm{X}$ & $\mathrm{X}$ & $\mathrm{X}$ & $\mathrm{X}$ & $\mathrm{X}$ \\
\hline Generic and disease-specific HRQL assessment & $\mathrm{X}$ & $\mathrm{X}$ & & $\mathrm{X}$ & & $\mathrm{X}$ & & $\mathrm{X}$ & & $\mathrm{X}$ \\
\hline Symptoms and signs of the PTS & & $\mathrm{X}$ & $\mathrm{X}$ & $\mathrm{X}$ & $\mathrm{X}$ & $\mathrm{X}$ & $\mathrm{X}$ & $\mathrm{X}$ & $\mathrm{X}$ & $\mathrm{X}$ \\
\hline Blood sampling & $\mathrm{X}$ & & & $\mathrm{X}$ & & & & & & \\
\hline Leg vein ultrasonography (in patients with index DVT only) & & $\mathrm{X}$ & & & & & & & & \\
\hline Echocardiography (in patients with index PEonly) & $\mathrm{X}$ & & & & & & & & & \\
\hline Medical resource utilization & $\mathrm{X}$ & $\mathrm{X}$ & & $\mathrm{X}$ & & $\mathrm{X}$ & & $\mathrm{X}$ & & $\mathrm{X}$ \\
\hline
\end{tabular}

$V T E$ venous thromboembolism, $H R Q L$ health-related quality of life, $P T S$ postthrombotic syndrome, $D V T$ deep vein thrombosis, $P E$ pulmonary embolism 
Table 2 Data collected

\begin{tabular}{|c|c|}
\hline Data collected & Variables \\
\hline \multicolumn{2}{|l|}{ Patient baseline characteristics } \\
\hline $\begin{array}{l}\text { Demographic and socioeconomic } \\
\text { factors }\end{array}$ & Age, gender, race, education level, and insurance and living status \\
\hline VTE-related risk factors & $\begin{array}{l}\text { Recent immobilization, cancer, prior VTE, estrogen therapy, known thrombophilia, arterial } \\
\text { hypertension, smoking, physical activity, acute heart failure, recent sepsis, acute respiratory failure, } \\
\text { acute rheumatic disease, recent stroke, recent major surgery, inflammatory bowel disease, and } \\
\text { family history of VTE }\end{array}$ \\
\hline History and physical examination & $\begin{array}{l}\text { VTE-related symptoms, vital parameters, signs and symptoms of the PTS [27], and } \\
\text { electrocardiographic findings }\end{array}$ \\
\hline Bleeding risk factors & $\begin{array}{l}\text { History of stroke, history of gastrointestinal bleeding, history of major bleeding, recent myocardial } \\
\text { infarction, diabetes mellitus, renal failure, anemia, thrombocytopenia, liver disease, and } \\
\text { concomitant use of antiplatelet treatment }\end{array}$ \\
\hline VTE event & Type (DVT and/or PE) and localization \\
\hline $\begin{array}{l}\text { Initial VTE-related processes } \\
\text { of care }\end{array}$ & Diagnostic strategy, type of treatment \\
\hline VTE-related complications & $\begin{array}{l}\text { VTE recurrence, bleeding event (minor, major), mortality, chronic thromboembolic pulmonary } \\
\text { hypertension, heparin-induced thrombocytopenia, and signs and symptoms of the PTS [27] }\end{array}$ \\
\hline $\begin{array}{l}\text { Generic and disease specific } \\
\text { health-related quality of life }\end{array}$ & $\begin{array}{l}\text { Short Form } 36 \text { Health Survey Questionnaire (SF-36), VEINES quality of life and symptom severity } \\
\text { [VEINES-QOL/Sym] questionnaire for patients with symptomatic index DVT and the Pulmonary } \\
\text { Embolism Quality of Life [PEmb-QoL] questionnaire for patients with symptomatic index PE }\end{array}$ \\
\hline Leg vein ultrasonography & Signs of residual vein thrombosis [46] \\
\hline Echocardiography & Signs of right-ventricular dysfunction $[47,48]$ \\
\hline Blood collection & Hemostasis tests, biomarkers, DNA and RNA analyses ${ }^{a}$ \\
\hline Medical resource utilization & $\begin{array}{l}\text { VTE-related processes of care, length of the index hospitalization, number of VTE-related physician } \\
\text { and emergency department visits, acute and chronic care hospital and nursing home admissions }\end{array}$ \\
\hline
\end{tabular}

$V T E$ venous thromboembolism, PTS postthrombotic syndrome, DVT deep vein thrombosis, $P E$ pulmonary embolism

${ }^{a}$ At baseline: D-dimer ELISA (Vidas), fibrinogen, factor V Leiden mutation, prothrombin G20210A mutation, $N$-terminal pro-brain natriuretic peptide, genotyping cytochrome P450 2C9 (CYP2C9), genotyping vitamin K epoxide reductase complex subunit 1 (VKORC1), ultra sensitive troponin, ultra sensitive C-reactive protein; at 12 months after the index VTE: D-dimer ELISA (Vidas), fibrinogen, antithrombin, protein C, protein S, lupus anticoagulant, anti-beta-2-glycoprotein antibodies, anticardiolipin antibodies, homocystein, factor VIII, factor IX, factor XI

intramuscular with compartment syndrome), a bleeding with a reduction of hemoglobin $\geq 20 \mathrm{~g} / \mathrm{l}$, or a bleeding leading to the transfusion $\geq 2$ units of packed red blood cells [25]. We also collect information on all bleeding events that require medical attention (e.g., a physician consultation or a visit at the emergency department).

The PTS is defined as a score of $\geq 5$ based on the Villalta scale [26]. The Villalta scale is well validated [28], has good to excellent inter-observer reliability [29], and is responsive to clinical change [31, 32].

We assess outcomes using patient or proxy interviews, interview of the patient's primary care physician, and/or hospital chart review. A committee of three blinded clinical experts adjudicates all outcomes and classifies the cause of all deaths as definitely due to PE, possibly due to PE, due to major bleeding, or due to another cause $[25,30]$. Final classifications are made on the basis of the full consensus of this committee.

Study nurses collect clinical patient variables and screen for the presence of the PTS using the Villalta scale (Table 2) [27]. Study nurses also collect information on initial VTE-related processes of care that potentially have an impact on medical and economic patient outcomes [31-34], including diagnostic strategy used to diagnose VTE, anticoagulation-related practices, prescription of compression stockings in patients with DVT, and invasive treatments (systemic thrombolysis, catheterbased interventions, insertion of a vena caval filter, or surgical thromboembolectomy) [32]. To determine direct costs of medical care, study nurses collect detailed information about patients' demographic and socioeconomic factors, VTE-related risk factors, history and physical examination, bleeding risk factors, initial VTE-related processes of care, VTE-related complications, symptoms and signs of the PTS, and health-related quality of life. Utilized resources will be transformed in cost measures using Swiss insurance reimbursement standards (www.tarmedsuisse.ch; www.swissdrg.ch).

\section{Laboratory variables}

At the time of study enrolment, information on routine laboratory tests (blood count, serum chemistry, and basic 
coagulation studies, such as the international normalized ratio) was collected and a baseline blood sample was drawn from each consenting patient. The blood samples were locally processed, packed in dry ice, and sent to the SWITCO65+ project biobank where the samples are stored in a $-80{ }^{\circ} \mathrm{C}$ high capacity freezer.

Because fibrinogen, antithrombin, protein $\mathrm{C}$ and $\mathrm{S}$, antiphospholipid antibodies, and factor VIII, IX, and XI levels may be influenced by the presence of acute thrombosis or ongoing anticoagulation, these parameters are measured in a second fasting blood sample at 12 months after the index VTE. In patients who are still receiving vitamin $\mathrm{K}$ antagonists at that time, vitamin- $\mathrm{K}$ dependant coagulation factors (protein $\mathrm{C}$ and $\mathrm{S}$, factor IX) are not measured. Low levels of coagulation inhibitors (antithrombin, protein $\mathrm{C}$ or $\mathrm{S}$ ) and the presence of antiphospholipid antibodies are confirmed in a second blood sample. In total, the SWITCO65+ biobank contains $105 \mathrm{ml}$ blood from each participant. All individual laboratory tests are performed in a single reference laboratory (Table 2).

A biobank has been established to collect and store serum, plasma, and DNA and RNA samples to explore future, yet unknown biological prognostic markers for VTE and treatment responses. To ensure optimal sample storing and processing, our study biobank follows established quality standards [35].

\section{Additional imaging exams}

Patients with symptomatic PE underwent transthoracic echocardiography at baseline to assess the presence of right ventricular dysfunction, a parameter that is associated with increased overall mortality following PE [36]. On-site cardiologists performed echocardiographic exams according to a standardized protocol.

Because residual vein thrombosis is known to be a risk factor of VTE recurrence [37], each patient with symptomatic proximal DVT had a leg vein ultrasonography based on a standard protocol at three months after enrolment. On-site vascular physicians performed all exams according to a standardized protocol.

\section{Health-related quality of life assessment}

We assess patients' generic health-related quality of life at baseline and during follow-up using the standard Short Form 36 Health Survey Questionnaire. We evaluate diseasespecific health-related quality of life using validated questionnaires: the VEINES quality of life and symptom severity (VEINES-QOL/Sym) questionnaire for patients with symptomatic index DVT and the Pulmonary Embolism Quality of Life (PEmb-QoL) questionnaire for patients with symptomatic index PE [38, 39]. All questionnaires are selfadministered.

Sample size calculation and planned statistical analyses

We based our sample size calculation on the clinical relevance of risk factors for VTE recurrence. A risk factor was considered clinically relevant if its prevalence is $\geq 10 \%$ in elderly patients with VTE and if this risk factor increases the risk of recurrent VTE by $\geq 2$-fold during a 4-year follow-up period [40]. Assuming a conservative baseline VTE recurrence rate of $15 \%$ at four years, a sample size of $\geq 649$ elderly patients with VTE was needed to detect a hazard ratio of $\geq 2.0$ for VTE recurrence, using a $80 \%$ power and a 2-sided alpha level of 0.05 [41-43]. Estimating that up to $30 \%$ of patients would die from nonVTE-related causes or drop out for other reasons during the 4-year follow-up, an initial sample size of about 1,000 patients was necessary.

The cumulative incidence of recurrent VTE will be calculated by Kaplan-Meier survival analysis. The Coxproportional hazards model will be used to evaluate the association between clinical, biological, and radiographic predictors and the time of VTE recurrence. To account for clustering of patients within a given center, we will include a fixed-center effect in the Cox-proportional hazard model. We will use the same survival methods to evaluate the association between predictors and major bleeding, death, and the PTS.

Mean scores for the SF-36, VEINES-QOL/Sym, and PEmb-QoL questionnaire will be computed at baseline, at 3, 12, 24, 36, and 48 months. Differences in mean scores over time will be analyzed using repeated-measures analysis of variance. Proportions of patients who worsened from the previous time point will be calculated. Potential determinants (clinical patient factors, processes of care) of worsening health-related quality of life scores from 3, 12, 24, 36, and 48 months will be evaluated using logistic regression, with the change in score (dichotomized as improved versus worse) as the dependent variable.

To account for differences in follow-up time, costs of care for each patient will be expressed as annualized costs and weighted for the number of months a given patient was observed. A linear regression model will be used to study the association between costs of care and clinical patient factors, processes of care, and medical outcomes.

\section{Preliminary results}

Between September 8, 2009, and March 31, 2012, a total of 1,863 patients with VTE were screened (Fig. 1). We excluded $462(24.8 \%)$ who had at least one of the 
Fig. 1 Flow chart

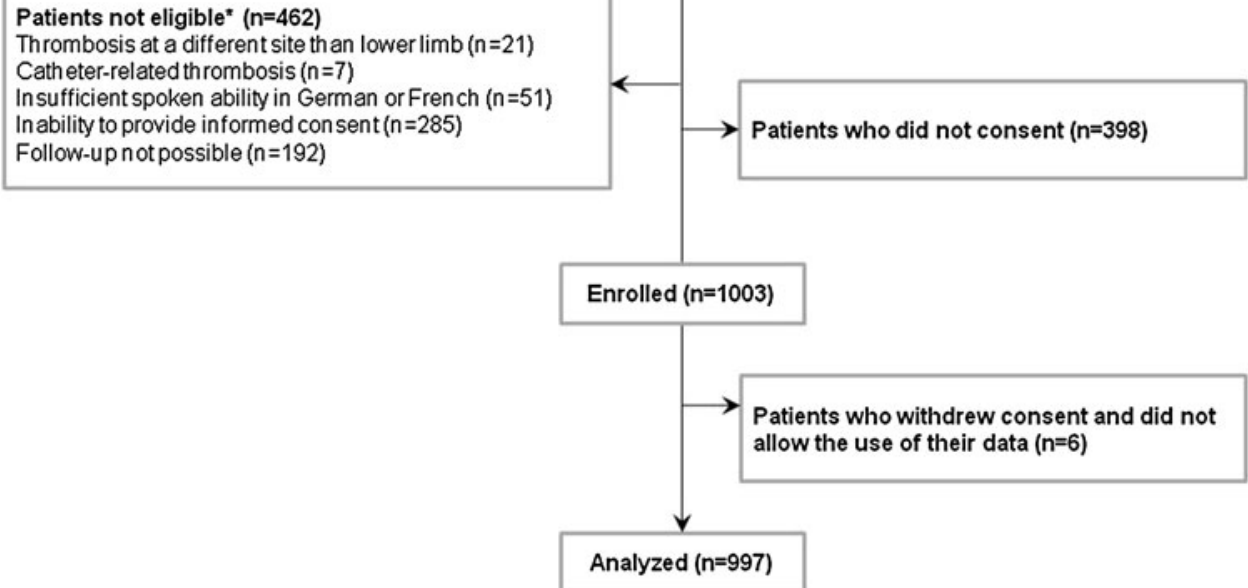

following exclusion criteria: inability to provide informed consent $(n=285)$, follow-up not possible $(n=192)$, insufficient ability to speak German or French $(n=51)$, thrombosis at different site than lower limb $(n=21)$, or catheter-related thrombosis $(n=7)$, leaving a sample of 1,401 eligible patients. After the exclusion of 398 patients who refused to provide informed consent, our initial study sample comprised 1,003 patients $(53.8 \%$ of initially screened patients). The baseline characteristics of the study sample are shown in Table 3. Non-enrolled patients were statistically significantly older (mean age 78 vs. 76 years; $P=0.001$ ), more likely to be women (59 vs. $47 \% ; P<0.001$ ), and were somewhat less likely to have symptomatic PE (65 vs. $69 \% ; P=0.053$ ) than enrolled patients.

By October 16, 2012, six patients had withdrawn their consent and did not allow the use of their data. Of the 997 remaining patients, after an average follow-up time of 512 days, $799(79.7 \%)$ patients were still actively participating, 150 (15\%) had died, 47 (4.7\%) had withdrawn their consent allowing the use of their data and one $(0.1 \%)$ had been lost to follow-up. The 53 patients who withdrew their consent were statistically significantly more likely to be women (68 vs. $46 \% ; P=0.003$ ) and had a significantly longer length of hospital stay (15.8 vs. 9.4 days; $P<0.001)$ than the 950 patients who continued participating, was lost to follow-up or who died.

The enrolment of new patients was terminated on March 31, 2012 when the targeted patient sample size was achieved. Of the 1,003 initially enrolled patients, the majority $(51.7 \%)$ is aged $\geq 75$ years and $52.7 \%$ are men (Table 3). Virtually all patients are Caucasians (99.8\%). Patients from all educational levels are well represented in the study. A substantial proportion of patients has comorbid diseases, such as active cancer, chronic lung disease, or heart failure. Overall, $69.3 \%$ of patients had PE with or without DVT. Most patients $(81.2 \%)$ were treated in the hospital. Overall, $48.6 \%$ of patients received low-molecularweight heparin as initial antithrombotic treatment.

The vast majority of patients completed the baseline SF-36 (89.9 \%), VEINES-QOL/Sym (88.7 \%), and PEmbQoL (86.2 \%) questionnaires. Baseline blood samples are available in 905 (90.9 \%) of enrolled patients. Overall data completeness is excellent, with less than $5 \%$ missing values.

\section{Discussion}

The SWITCO65+ study is a multicentre prospective cohort aiming to study which clinical and biological predictors and processes of care drive long-term medical outcomes, quality of life, and medical resource utilization in 1,003 elderly patients with acute VTE. After an average follow-up time of 512 days, 799 (79.7\%) patients were still actively participating.

Our cohort study has several strengths. First, given the high incidence of VTE and the lack of data for elderly patients with VTE, a cohort project focusing on the outcomes of elderly patients with VTE is innovative and relevant from a public health point of view. To our knowledge, our cohort study is the most comprehensive attempt to study the impact of clinical, biological, and radiologic predictors on clinically relevant outcomes, health-related quality of life, and medical resource utilization in elderly patients with VTE. Second, a particular 
Table 3 Baseline characteristics of the full cohort

\begin{tabular}{|c|c|}
\hline Characteristics & $n / N(\%)^{\mathrm{a}}$ \\
\hline Male gender & $529 / 1003(52.7)$ \\
\hline \multicolumn{2}{|l|}{ Age, years } \\
\hline $65-75$ & $484 / 1003(48.3)$ \\
\hline $75-85$ & $385 / 1003(38.4)$ \\
\hline$>85$ & 134/1003 (13.4) \\
\hline Caucasian race & 994/996 (99.8) \\
\hline \multicolumn{2}{|l|}{ Education level } \\
\hline Less than high school & $547 / 992(55.1)$ \\
\hline High school graduate & $252 / 992(25.4)$ \\
\hline University graduate & 193/992 (19.5) \\
\hline \multicolumn{2}{|l|}{ Living status } \\
\hline At home with someone else & $631 / 994(63.5)$ \\
\hline At home alone & $339 / 994(34.1)$ \\
\hline In nursing home & 24/994 (2.4) \\
\hline \multicolumn{2}{|l|}{ Comorbid diseases } \\
\hline Active cancer ${ }^{\mathrm{b}}$ & $157 / 995(15.8)$ \\
\hline Chronic lung disease & $136 / 995(13.7)$ \\
\hline Heart failure & 77/995 (7.7) \\
\hline Prior history of VTE & 283/995 (28.4) \\
\hline \multicolumn{2}{|l|}{ Index VTE event } \\
\hline DVT only & $308 / 1003(30.7)$ \\
\hline PE only & $558 / 1003(55.6)$ \\
\hline Both DVT and PE & $137 / 1003(13.7)$ \\
\hline \multicolumn{2}{|l|}{ Site of treatment } \\
\hline Inpatient $^{\mathrm{c}}$ & $802 / 995(81.2)$ \\
\hline Outpatient & $187 / 995(18.8)$ \\
\hline \multicolumn{2}{|l|}{ Initial treatment } \\
\hline Low-molecular-weight heparin & $468 / 960(48.7)$ \\
\hline Unfractionated heparin & $332 / 960(34.6)$ \\
\hline Fondaparinux & $159 / 960(16.6)$ \\
\hline Danaparoid & $1 / 960(0.1)$ \\
\hline
\end{tabular}

$V T E$ venous thromboembolism, $D V T$ deep vein thrombosis, $P E$ pulmonary embolism

${ }^{a}$ Denominators are changing because the information was not available in all patients

b Defined as cancer that required therapy (surgery, chemotherapy, and/or radiotherapy) during the last 3 months

c Overall, 184 inpatients developed VTE during a hospitalization for another reason

strength is the focus on health-related quality of life measures. Given their reduced life expectancy, health-related quality of life aspects may be particularly relevant in the elderly. Third, because factors that drive medical resource utilization have not been prospectively examined in elderly patients with VTE, our cohort will improve our understanding of what drives cost of care in such patients. Fourth, we have established a biobank including DNA and RNA samples. These samples can be used to study future, yet unknown predictors of VTE-related prognosis. Fifth, SWITCO65+ benefits from a professional data management that includes central monitoring and regular data quality control measures. Further strengths are the low dropout rate of $4.8 \%$ and the near-complete data collection.

Our study has several potential limitations. First, our study patients were recruited at all five Swiss university hospitals (two of which serve also as community hospital) and four high-volume non-university hospitals and therefore, our cohort is not entirely population-based. Given the decentralized structure of the Swiss health care system, the high complexity and costs of baseline and follow-up assessments, a broader recruitment at small-volume hospital sites, would not have been logistically and financially feasible. However, because we included consecutive VTE patients from in- and outpatient services at university and non-university hospitals, we believe our study sample to be fairly representative for Swiss patients with VTE. Second, although we offered home visits and enrolled patients with mild to moderate cognitive disorders, we cannot exclude the possibility that the sickest patients are underrepresented in our cohort because patients suffering from severe dementia or terminal illness were excluded from participation. Another common reason for non-enrollment was refusal to participate (21.4\% of screened patients), most probably because of the high number and complexity of baseline and follow-up assessments, a known obstacle to study participation in the elderly [44]. However, given the high study burden, the $53.8 \%$ enrollment rate that we achieved is laudable for a prospective cohort study focusing on elderly patients and compares well with other cardiovascular cohort studies of older persons. For example, the Cardiovascular Health Study enrolled $39.6 \%$ of elderly subjects with whom contact was made [45]. Third, $99.8 \%$ of our study patients were Caucasians. Thus, our results may not be generalizable to other racial or ethnic groups. Finally, because the present paper focuses on the study rationale and methods and the follow-up is still ongoing, we did not present medical outcome data.

All data are centrally managed and stored at the Clinical Trials Unit of the University of Bern, Switzerland. The study biobank is located at the Service and Central Laboratory of Hematology at the Lausanne University Hospital, Lausanne, Switzerland. Additional information about the cohort, such as the study protocol, data collection forms, study progress, ongoing nested projects, and planned or published articles, can be found on the study website (www.switco65.ch) or at ClinicalTrials.gov (identifier NCT00973596). The Steering Committee of SWITCO65+ encourages national and international collaborative research projects related to SWITCO65+, including sharing anonymized data and biological samples. All submitted projects are peer-reviewed and subject to a final decision by the Steering Committee based on 
the following criteria: (1) ethical considerations, (2) originality, (3) validity of the methods used, and (4) feasibility. Any requests for access to SWITCO65+ data or material are to be submitted to the Steering Committee using the study Subproject Proposal Form (available at www.switco65.ch).

\section{References}

1. Rosendaal FR, Vanhv A, Doggen CJ (2007) Venous thrombosis in the elderly. J Thromb Haemost 5(Suppl 1):310-317

2. Cushman M, Tsai AW, White RH, Heckbert SR, Rosamond WD, Enright $\mathrm{P}$ et al (2004) Deep vein thrombosis and pulmonary embolism in two cohorts: the longitudinal investigation of thromboembolism etiology. Am J Med 117:19-25

3. Kniffin WD Jr, Baron JA, Barrett J, Birkmeyer JD, Anderson FA $\mathrm{Jr}$ (1994) The epidemiology of diagnosed pulmonary embolism and deep venous thrombosis in the elderly. Arch Intern Med 154: 861-866

4. Naess IA, Christiansen SC, Romundstad P, Cannegieter SC, Rosendaal FR, Hammerstrom J (2007) Incidence and mortality of venous thrombosis: a population-based study. J Thromb Haemost 5:692-699

5. Oger E (2000) Incidence of venous thromboembolism: a community-based study in Western France. EPI-GETBP Study Group. Groupe d'Etude de la Thrombose de Bretagne Occidentale. Thromb Haemost 83:657-660

6. Spencer FA, Gore JM, Lessard D, Emery C, Pacifico L, Reed G et al (2008) Venous thromboembolism in the elderly. A community-based perspective. Thromb Haemost 100:780-788

7. Robine JM, Paccaud F (2005) Nonagenarians and centenarians in Switzerland, 1860-2001: a demographic analysis. J Epidemiol Community Health 59:31-37

8. (OFS) Office fédéral de la santé publique [Internet] Les scénarios de l'évolution de la population de la Suisse 2010-2060. Available from: http://www.bfs.admin.ch/bfs/portal/fr/index/news/publikat ionen.Document.132793.pdf. Accessed 22 Jan 2013

9. Tagalakis V, Kahn SR (2009) The epidemiology of venous thromboembolism in the elderly: a population-based study [abstract]. American Society of Hematology (ASH), New Orleans

10. Cooke CR, Erickson SE, Watkins TR, Matthay MA, Hudson LD, Rubenfeld GD (2010) Age-, sex-, and race-based differences among patients enrolled versus not enrolled in acute lung injury clinical trials. Crit Care Med 38:1450-1457

11. Lee PY, Alexander KP, Hammill BG, Pasquali SK, Peterson ED (2001) Representation of elderly persons and women in published randomized trials of acute coronary syndromes. JAMA 286: 708-713

12. Link RP (2008) National Heart, Lung, and Blood Institute programs for deep vein thrombosis. Arterioscler Thromb Vasc Biol 28:392-393

13. Silverstein RL, Bauer KA, Cushman M, Esmon CT, Ershler WB, Tracy RP (2007) Venous thrombosis in the elderly: more questions than answers. Blood 110:3097-3101

14. Engbers MJ, van Hylckama Vlieg A, Rosendaal FR (2010) Venous thrombosis in the elderly: incidence, risk factors and risk groups. J Thromb Haemost 8:2105-2112

15. Dauzat M, Laroche JP, Deklunder G, Ayoub J, Quere I, Lopez FM et al (1997) Diagnosis of acute lower limb deep venous thrombosis with ultrasound: trends and controversies. J Clin Ultrasound 25:343-358

16. Fraser DG, Moody AR, Morgan PS, Martel AL, Davidson I (2002) Diagnosis of lower-limb deep venous thrombosis: a prospective blinded study of magnetic resonance direct thrombus imaging. Ann Intern Med 136:89-98

17. Fraser DG, Moody AR, Davidson IR, Martel AL, Morgan PS (2003) Deep venous thrombosis: diagnosis by using venous enhanced subtracted peak arterial MR venography versus conventional venography. Radiology 226:812-820

18. Enden T, Sandvik L, Klow NE, Hafsahl G, Holme PA, Holmen LO et al (2007) Catheter-directed venous thrombolysis in acute iliofemoral vein thrombosis-the CaVenT study: rationale and design of a multicenter, randomized, controlled, clinical trial (NCT00251771). Am Heart J 154:808-814

19. Kearon C, Ginsberg JS, Hirsh J (1998) The role of venous ultrasonography in the diagnosis of suspected deep venous thrombosis and pulmonary embolism. Ann Intern Med 129: 1044-1049

20. Righini M, Paris S, Le Gal G, Laroche JP, Perrier A, Bounameaux H (2006) Clinical relevance of distal deep vein thrombosis. Review of literature data. Thromb Haemost 95:56-64

21. Le Gal G, Righini M, Sanchez O, Roy PM, Baba-Ahmed M, Perrier A et al (2006) A positive compression ultrasonography of the lower limb veins is highly predictive of pulmonary embolism on computed tomography in suspected patients. Thromb Haemost 95:963-966

22. Buller HR, Davidson BL, Decousus H, Gallus A, Gent M, Piovella F et al (2003) Subcutaneous fondaparinux versus intravenous unfractionated heparin in the initial treatment of pulmonary embolism. N Engl J Med 349:1695-1702

23. Mello MM, Wolf LE (2010) The Havasupai Indian tribe caselessons for research involving stored biologic samples. N Engl J Med 363:204-207

24. (1997) Low-molecular-weight heparin in the treatment of patients with venous thromboembolism. The Columbus Investigators. N Engl J Med 337:657-662

25. Schulman S, Kearon C (2005) Definition of major bleeding in clinical investigations of antihemostatic medicinal products in non-surgical patients. J Thromb Haemost 3:692-694

26. Kahn SR, Partsch H, Vedantham S, Prandoni P, Kearon C (2009) Definition of post-thrombotic syndrome of the leg for use in clinical investigations: a recommendation for standardization. J Thromb Haemost 7:879-883

27. Villalta S, Bagatella P, Piccioli A, Lensing AW, Prins MH, Prandoni P (1994) Assessment of validity and reproducibility of a clinical scale for the post-thrombotic syndrome [abstract]. Haemostasis $24: 158 \mathrm{~A}$

28. Kahn SR (2009) Measurement properties of the Villalta scale to define and classify the severity of the post-thrombotic syndrome. J Thromb Haemost 7:884-888

29. Rodger MA, Kahn SR, Le Gal G, Solymoss S, Chagnon I, Anderson DR et al (2008) Inter-observer reliability of measures to assess the post-thrombotic syndrome. Thromb Haemost 100: $164-166$

30. Jakobsson C, Jimenez D, Gomez V, Zamarro C, Mean M, Aujesky D (2010) Validation of a clinical algorithm to identify low-risk patients with pulmonary embolism. J Thromb Haemost 8: 1242-1247

31. Roy PM, Meyer G, Vielle B, Le Gall C, Verschuren F, Carpentier $\mathrm{F}$ et al (2006) Appropriateness of diagnostic management and outcomes of suspected pulmonary embolism. Ann Intern Med 144:157-164

32. Buller HR, Agnelli G, Hull RD, Hyers TM, Prins MH, Raskob GE (2004) Antithrombotic therapy for venous thromboembolic disease: The Seventh ACCP Conference on Antithrombotic and Thrombolytic Therapy. Chest 126:401S-428S

33. Gallus A, Jackaman J, Tillett J, Mills W, Wycherley A (1986) Safety and efficacy of warfarin started early after submassive venous thrombosis or pulmonary embolism. Lancet 2:1293-1296 
34. Rosiello RA, Chan CK, Tencza F, Matthay RA (1987) Timing of oral anticoagulation therapy in the treatment of angiographically proven acute pulmonary embolism. Arch Intern Med 147: 1469-1473

35. Sciences SAoM [Internet] Biobanks: obtainment, preservation and utilisation of human biological material: medical-ethical guidelines and recommendations. Available from: http://www. samw.ch/en/Ethics/Guidelines/Currently-valid-guidelines.html. Accessed 22 Jan 2013

36. Sukhija R, Aronow WS, Lee J, Kakar P, McClung JA, Levy JA et al (2005) Association of right ventricular dysfunction with inhospital mortality in patients with acute pulmonary embolism and reduction in mortality in patients with right ventricular dysfunction by pulmonary embolectomy. Am J Cardiol 95:695-696

37. Prandoni P, Lensing AW, Prins MH, Bernardi E, Marchiori A, Bagatella $\mathrm{P}$ et al (2002) Residual venous thrombosis as a predictive factor of recurrent venous thromboembolism. Ann Intern Med 137:955-960

38. Kahn SR, Lamping DL, Ducruet T, Arsenault L, Miron MJ, Roussin A et al (2006) VEINES-QOL/Sym questionnaire was a reliable and valid disease-specific quality of life measure for deep venous thrombosis. J Clin Epidemiol 59:1049-1056

39. Cohn DM, Nelis EA, Busweiler LA, Kaptein AA, Middeldorp S (2009) Quality of life after pulmonary embolism: the development of the PEmb-QoL questionnaire. J Thromb Haemost 7: 1044-1046

40. Bradford-Hill A (1965) The environment and disease: association or causation? Proc R Soc Med 58:295-300
41. Freedman LS (1982) Tables of the number of patients required in clinical trials using the logrank test. Stat Med 1:121-129

42. Hansson PO, Sorbo J, Eriksson H (2000) Recurrent venous thromboembolism after deep vein thrombosis: incidence and risk factors. Arch Intern Med 160:769-774

43. Kyrle PA, Minar E, Bialonczyk C, Hirschl M, Weltermann A, Eichinger S (2004) The risk of recurrent venous thromboembolism in men and women. N Engl J Med 350:2558-2563

44. McMurdo ME, Roberts H, Parker S, Wyatt N, May H, Goodman $\mathrm{C}$ et al (2011) Improving recruitment of older people to research through good practice. Age Ageing 40:659-665

45. Tell GS, Fried LP, Hermanson B, Manolio TA, Newman AB, Borhani NO (1993) Recruitment of adults 65 years and older as participants in the Cardiovascular Health Study. Ann Epidemiol 3:358-366

46. Siragusa S, Malato A, Anastasio R, Cigna V, Milio G, Amato C et al (2008) Residual vein thrombosis to establish duration of anticoagulation after a first episode of deep vein thrombosis: the "DACUS" study. Blood 112:511-515

47. Kucher N, Rossi E, De Rosa M, Goldhaber SZ (2005) Prognostic role of echocardiography among patients with acute pulmonary embolism and a systolic arterial pressure of $90 \mathrm{~mm} \mathrm{Hg}$ or higher. Arch Intern Med 165:1777-1781

48. Sanchez O, Trinquart L, Colombet I, Durieux P, Huisman MV, Chatellier G et al (2008) Prognostic value of right ventricular dysfunction in patients with haemodynamically stable pulmonary embolism: a systematic review. Eur Heart J 29:1569-1577 